\title{
Higher Education in Albania Based on Harmonized Indicators of Gender Equality and the Status of Women
}

\author{
Dr. Daniela Kalaja \\ Dr. Fatlinda Berisha - Tahiri \\ Dr. Eliona Kulluri - Bimbashi \\ University of Tirana, Faculty of Social Sciences, Department of Social Work and Social Policy \\ dkalaja07@yahoo.com; fatlinda.berisha@gmail.com; elakulluri@yahoo.com
}

\author{
Doi:10.5901/jesr.2015.v5n3p99
}

\begin{abstract}
Higher education is a field in which there have been good achievements in terms of access for women and girls. Education is one of the values that have traditionally been evaluated by the Albanian society. The high level of education of women and girls in Albania shows that they are successful, and that education is important in achieving a higher status in the family and in society. Education is recognized worldwide as an important indicator of social and economic development of a society. The statistical data according to INSTAT pubications on "Women and men in Albania" as well as the official data of the Ministry of Education and Sport indicate that women are more successful than men in a substantial number of gender indices about education in Albania. Although women constitute the greatest number of graduadions in all levels of education and give a valuable contribution in the field of education, their social and economic status leaves much to be desired. This research aims to identify and analyze gender differences in education and their development tendencies, with an emphasis on academic achievements, through secondary analysis of statistical data in the education sector based on harmonized indicators of gender equality and women's status in Albania, findings from the analysis, evaluation reports and on national studies in this field. The national Group of Harmonized Gender Indicators, approved by the Government of Albania in 2010, is the official instrument to monitor the progress for the implementation of national and international commitments toward gender equality and women's human rights. In this article are analyzed and discussed the findings from the analysis of the three most important indicators of gender regarding higher education, respectively the indicators which refer to "Graduated students in public and private institutions of higher education in general", "Graduated students in public and private institutions of higher education according to fields of study and type of diploma" and the indicator which refers to "Scientific-teaching staff according to titles and degrees in public and private institutions of higher education". The career and academic achievements still remains a male-dominated field in Albania. The percentage of women involved in career and academic achievements continues to be very low and this figure is attributed to gender inequality in terms of attendance and benefit from higher levels of education. Academic women and girls perceive themselves as a minority group, in an environment completely dominated by men.
\end{abstract}

Keywords: Education, access, gender statistics, gender indicators, gender differences, gender approach, educational attainment / academic, career, gender sensitivity.

\section{Introduction}

Generally, the mechanisms used to monitor and evaluate programs, projects and policies of development have provided a perspective not so sensitive to gender differences, and sometimes they are completely "blind" to the special interests that characterize men and women.

The different impact that the development initiatives have on men and women (without excluding girls and boys) can be measured only if the indicators that assess it are sensitive to gender issues, which means that every individual needs and interests should be illustrated in a program, regardless of gender. This means that the distribution of social resources is done fairly and not unilaterally.

In order to measure the achievements of a project or program from the perspective of both genders, the measurement or assessment should be realized through the usage of sensitive indicators to gender. These indicators can measure changes related to gender in every society and in certain periods of time. At the same time, they may identify activities that are 'hidden' or 'unknown', which are not included in the gross national product, such as the realization of housework, child care and informal economy. The sensitive indicators on gender can serve as practical 
tools because the information obtained from them can be used to promote initiatives for achievement of gender equality and empowerment of women and girls. The indicators of education are one of the most important in determining the status of women in society, the education, as well, is one of the most reported areas from population censuses and administrative statistics (GADC, 2004).

The reflection of the educational situation in Albania from the gender approach through the secondary analysis of the statistical data in this section, constitutes an important component of the study, by reflecting the gendered reality of education, based on the harmonized indicators of gender equality and the status of women in Albania, respectively "The main indicators for promoting the right of women and young girls to attain a qualitative education" (MPCSSHB-UN Women, 2011, page.69).

The National Group of Harmonized Indicators of Gender approved by the Government of Albania in 2010 is the official instrument to monitor the improvements in the implementation of the national and international engagements towards gender equality and human rights for women.

In this research were used data published from The Ministry of Education and Science (MES) in "The annual statistical report on education from 2009 - 2010". In this study were analyzed the indicators which refer to existing data about education from the gender approach in the years 2004-2010. Time length is another important component which makes the usage of this method valuable in the investigation of time spread variables from the gender point of view.

Since, the existing statistics were of different patterns and not in the function of this study the data were reentered and were analyzed after the clearance from variables not significant for this research.

\section{Statistical Analysis}

To test if gender trends in time presented significant statistical differences, there was used the only statistical test that could be used in this case, based on the nature of this research, which were entirely the categorical variables. This is the Chi square test. The Chi square test tests if the statistical relation between two categorical variables is significant or not. This test reports the value of the statistical importance or the value of $P$. P value defines how much of a role does the chance play in the explanation of the observed statistical relation. It is set by agreement that if the observed statistical relation is called "statistically significant" it is accepted that the value of $P$ should be $\leq 0,05$ or $\leq 5 \%$.

In order that the Chi square test was applied the secondary data found in the MES report had to be converted in an appropriate form to be elaborated and analyzed. Due to this reason, the tables in this report were converted from a "published" form into electronic form, to be entered in Excel. Since in the report of MES was given only the total number and the number of females according to respective categories of variables, the researcher calculated the number of males based on this data. To accomplish the Chi square test it was necessary that the data of each table created in excel should be entered in the SPSS (Statistical Package for Social Sciences) statistical program. The respective models were created in SPSS in order to loyally reflect the tables created in excel. Being that the data from the MES report were aggregated, the values of the size of different groups in the study were transferred into SPSS and the calculated data were based on these values. Such technique created appropriate conditions for the application of the Chi square test in order that the statistical significance of gender differences was studied according to the above mentioned variables.

Afterwards, the absolute numbers were converted into percentages. In order to better highlight the gender tendency according to variables in the study, several diagrams in the forms of lines and columns were built based on the respective percentages. In every diagram was reported the value of $\mathrm{P}$ generated from the statistical Chi square test as applied previously.

In this article are analyzed, discussed and interpreted the findings from the analysis of the three most important indicators of gender regarding higher education, respectively the indicators which refer to "Graduated students in public and private institutions of higher education in general; Graduated students in public and private institutions of higher education according to fields of study and type of diploma" and the indicator which refers to "Scientific-teaching staff according to titles and degrees in public and private institutions of higher education".

\section{Findings}

\subsection{The indicator - Graduated students in public and private institutions of high education.}

In the following graphics is presented the percentage of students that graduated from high education of the public system, full time and part time, according to gender and academic years '04-'10. 

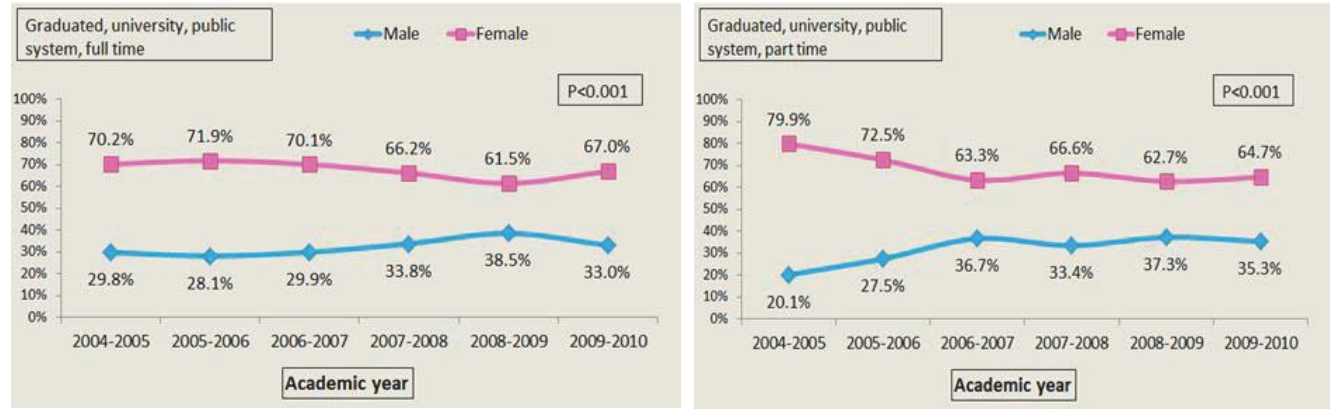

Graphic 1. The percentage of students that graduated from high education in the public system, full time and part time, according to gender and academic years '04-'10.

The percentage of females that graduated in high education full time is larger than that of males in every academic year in the study (the graphic on the left). The general trend is that the percentage of graduated females in high education full time has decreased significantly through the academic years in the study, even though it increases in 2009-2010. The proportion of graduated females/males from high public education on full time was higher in the years 2005-2006 (respectively 2.6:1,) and lower in 2008-2009 (respectively 1.6:1).

Also, the percentage of females graduated from high public education, part time is obviously higher than males in every academic year in the study. The tendency is that the proporton females/males is narrowed throughout the years (graphic 1, right). For instance, while in the academic year 2004-2005 for every male graduated in this educational profile, approximatly 4 females were graduated, in 2009-2010 for every male graduated, an average of 1.8 females were graduated.

In the following diagrams is reflected the percentage of students graduated in high education, public system, distance learning and in the private system full time, according to gender and academic years '04-'10.
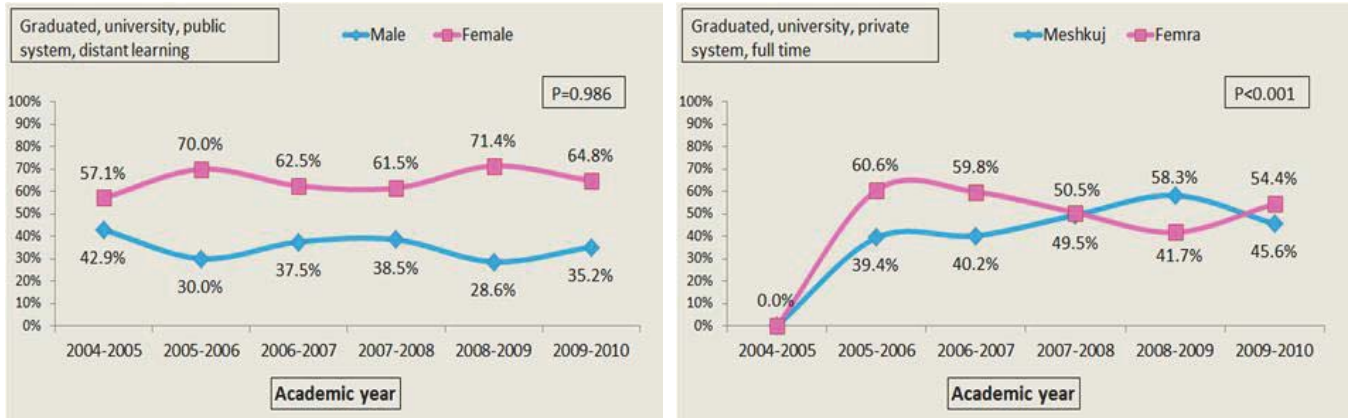

Graphic 2. The percentage of students graduated in high education, in the public system, distance learning and in the private system full time, according to gender and academic years '04-'10.

Even, according to, the graduations in high public education in the system of distance learning, the percentage of graduated females dominate towards the percentage of males graduated in every academic year in the study (graphic 2 , left). The report females/males graduated in this educational profile fluctuates during the years, varying from 1.3:1 in 2004-2005 (the lowest ratio) in 2.5:1 in 208-2009 (the highest ratio).

Whereas, according to the percentages of graduations in the high private education, full time, as seen in graphic 2 , right, gender tendencies do not reflect any obvious model alternating from time to time. However, the changes are statistically significant $(P<0.001)$. 
3.2 The indicator - Graduated students in public and private institutions of higher education by fields of study and type of diploma.

In the following graphics is presented the percentage of graduated students in public system, full-time, branch of Education Sciences and branch of Art and Humanitarian Sciences, by gender and type of diploma.
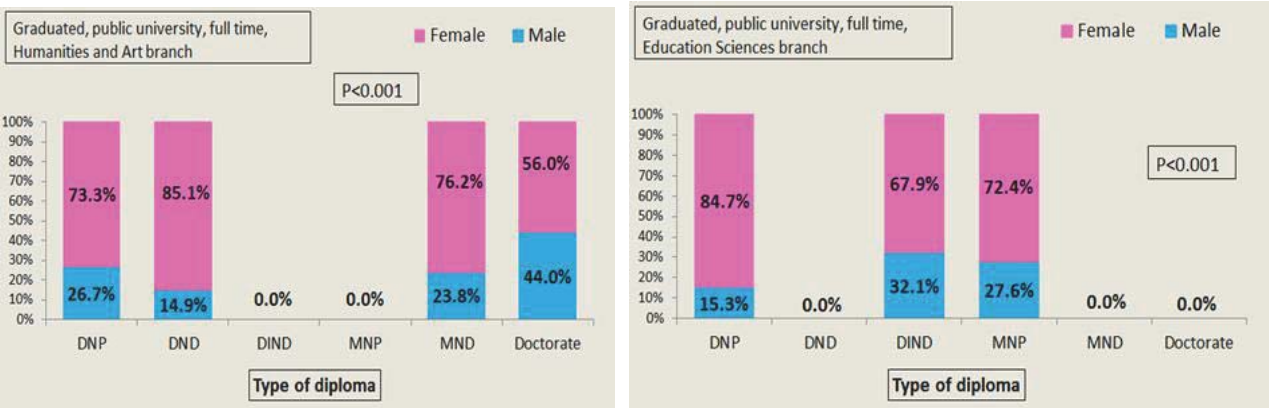

Graphic 3. Percentage of graduated students in the public system, branches of Humanitarian Sciences, Education Sciences and Art, by gender and type of diploma.

Gender differences are significant in graduation of full time students in public higher education, branch of Education Sciences, by type of diploma (Graphic 3, left). In any type of diploma, the majority of graduates are women: $85 \%$ of DNP graduates are women, in DIND are $67.9 \%$ and MNP are $72.4 \%$.

The similar tendencies are observed, in terms of the percentage among full time graduated women in public higher education, Humanitarian and Art branch by the type of diploma, where they (women) constitute the major proportion of graduates versus men for every type of diploma received in the study (Graphic 3, right).

In the following graphics is presented the percentage of full time graduated students in the public system, in Social Science, Business, Law and Sciences of Nature, by gender and type of diploma.
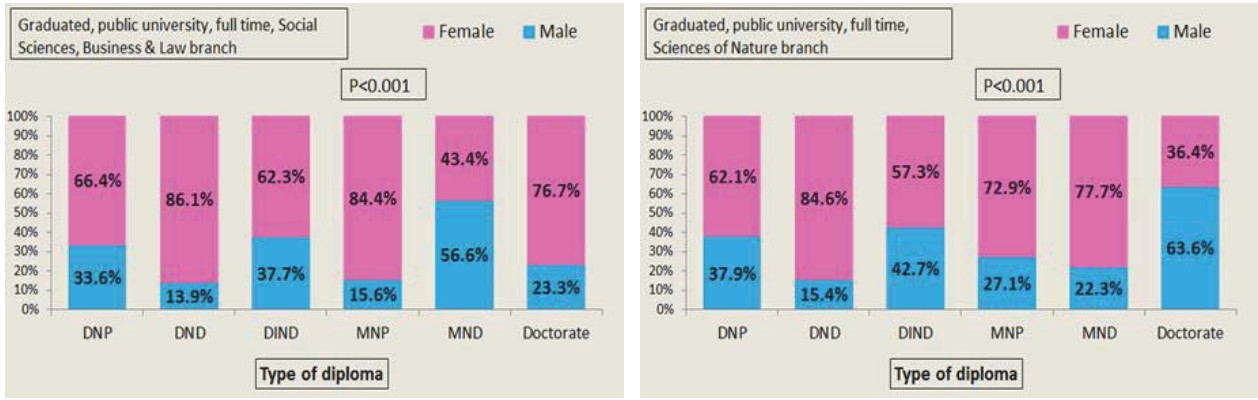

Graphic 4. Percentage of graduated students in public system, braches: Social Science, Business, Law and Sciences of Nature, by gender and type of diploma.

Gender differences by type of diplomas are significant in the graduation of full-time students in public higher education, branches of Social Sciences, Business and Law (Graphic 4, left). In any type of diploma, except MND of this branch, the majority of graduates are women. The gender differences are more emphasized in the Second Level Diploma, where for each graduated man there is an average of 6.2 graduated females, while the smaller gender differences belong to the MND where men actually occupy a larger proportion than women in this branch (ratio male/female is 1.3:1).

In the branch of Nature Sciences, gender differences in graduation by type of diploma are also significant (Graphic 4, right). In any type of diploma, except the PhD of this branch, the majority of graduates are women. More outlined gender differences are observed in the DND where for each graduated male are averaged 5.4 graduated females and 
the smaller gender differences belong to the Ph.D. degree because men constitute a larger proportion than women in this branch (ratio male/female is 1.7:1).

In the following graphicsis presented the percentage of full time graduated students in the public system, branch of Engineering Sciences, Agriculture and Veterinary branch, by gender and type of diploma.
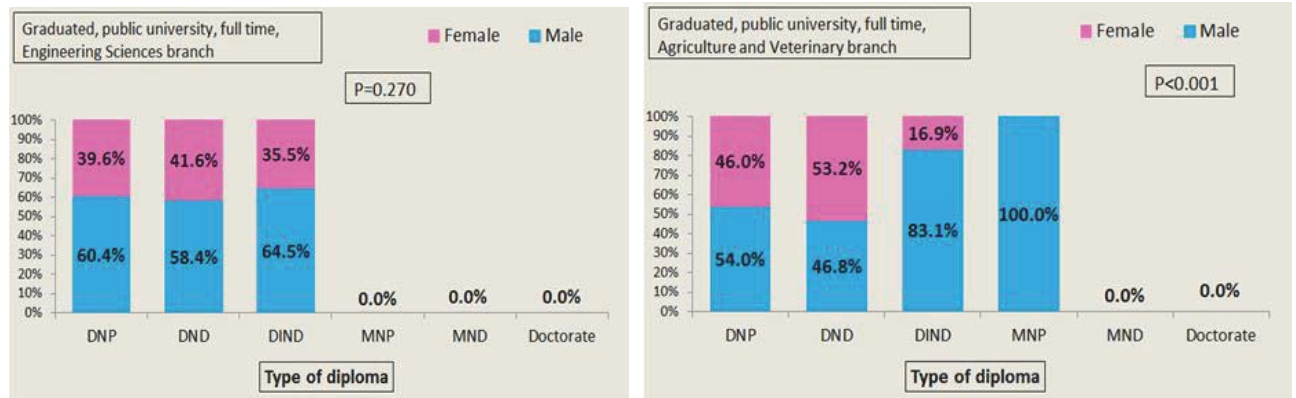

Graphic 5. Percentage of graduated students in the public system, branches of Engineering Sciences, and Agriculture and Veterinary Sciences, by gender and type of diploma.

Gender differences by type of diploma are significant in graduation of full-time students in public higher education in the branch of Engineering Sciences (Graphic 5, left). In any type of diploma, in this branch, the majority of graduates are males. Ratio male/female by type of degrees varies from 1.4:1 in DND to 1.8:1 in DIND (Graphic 5, left).

In the branch of Agriculture-Veterinary, gender differences in the graduation are significant by type of diploma. In any type of diploma in this branch, except DND, the majority of graduates are male. In MNP, $100 \%$ of males' graduates, in DIND approximately one in five graduates is a male (Graphic 5, right).

Regarding to gender differences of the part-time graduation in public system by type of diploma and fields of study, there was very little data or insufficient data to calculate them.

The same situation was noticed among full-time and part-time graduated students in private education, by type of diploma and fields of study. In the majority of these matrices, the numbers were zero, and therefore it was impossible to assess the gender differences of the graduation by type of diploma and fields of study.

\subsection{The Indicator - Academic-scientific staff by titles and degrees in public and private Institutions of Higher Education.}

\subsubsection{Full time academic staff}

In the following graphics is shown the percentage of full time academic staff, with the title of "Professor" and "Associate Professor", by gender and '04 - '10 academic years.
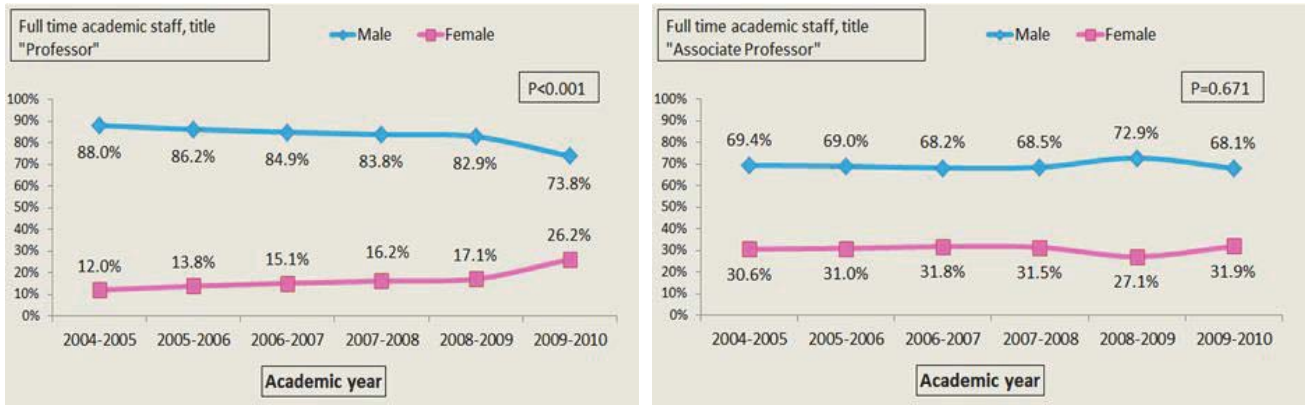

Graphic 6. Percentage of full time academic staff, with the title of "Professor" and "Associate Professor", by gender and '04-'10academic years 
During the time, gender differences of $\mathrm{PhD}$ full time academic staff are obvious and statistically significant, as shown in Graphic 45, left. The major percentage of full-time staff, titled Professor, is males. But, over the years, there is a relatively continuing and rapid decrease of this gender difference: in year 2004-2005 the ratio males/females of full-time professors with PhD degree in higher education system was 7.3:1 while in 2009-2010, which marked the largest decrease of gender differences, the ratio became 2.8:1 (Graphic. 6, left).

Regarding to gender differences in the full time academic staff with the title of Assistant Professor, there are no statistically significant changes over the times (Graphic. 6, right). Thus, in each academic year the proportion of male with this title is more than twice higher than females with this title, and this difference remained more or less at these levels during the entire academic years of this study.

3.4 In the following graphics is presented the percentage of full-time professors with and without "Doctor" Title by gender and academic years '04 - '10.
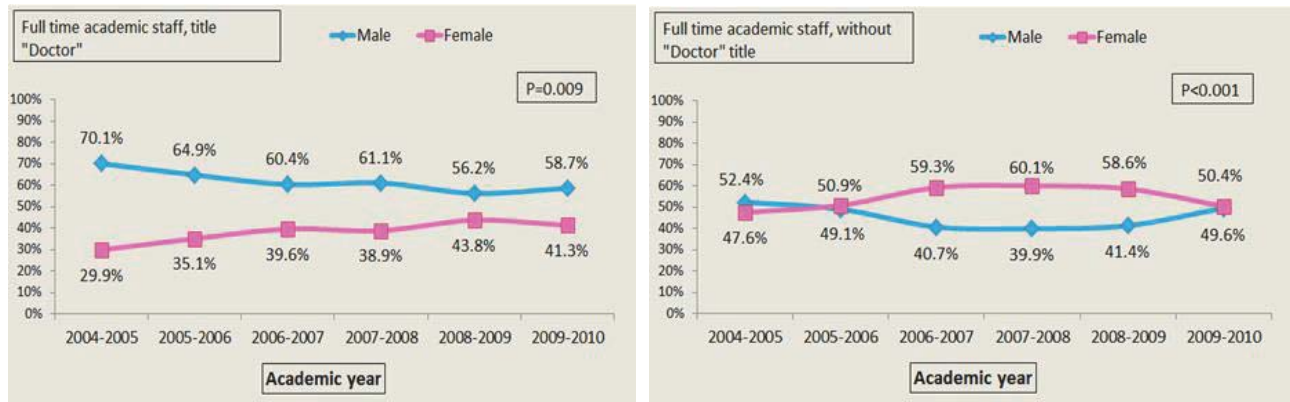

Graphic 7. Percentage of full time professors with or without "Doctor" Title, by gender and academic years '04-'10.

The gender differences of full time PHD academic staff have been clearly and statistically significant, as it is shown in Graphic 7, left. The largest percentage of staff, titled Doctor, are male in all academic years of the study, but over the years, there is noticed a very rapid and continuing decrease of this gender difference: in 2004-2005 the ratio males/females of full-time professors with Ph.D. in higher education system was 2.3:1 while in 2009-2010 the ratio was 1.4:1 (Graphic 7, left).

According to gender differences of full time academic staff without Ph.D., the changes are significant, during the academic years of the study (Graphic 7, right). But from the academic year 2005-2006 till 2008-2009 the percentage of females is higher than males (respectively, ratio female/male 1:1 and 1.4:1). However at the end of the study period, this ratio is still 1:1.

In the following graphic is shown the percentage of full time academic staff with title of "Directors of scientific researches" and "Masters of scientific researches", by gender and academic years '04 - '10.
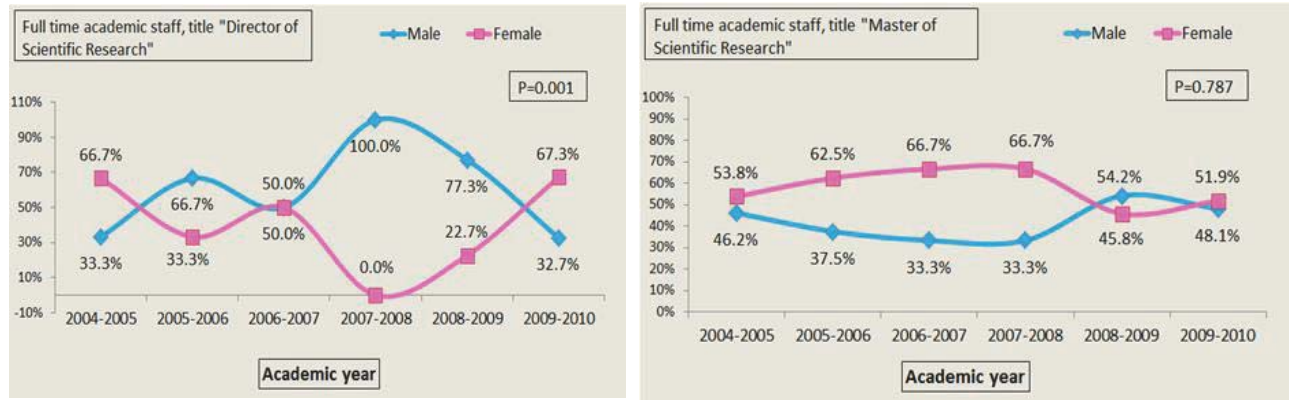

Graphic 8. Percentage of full time academic staff with title of "Directors of scientific researches" and "Master of scientific researchers", by gender and academic years '04-'10. 
Gender differences are statistically significant on the full time academic staff who are Directors of scientific researches, as it shown in Graphic 8, left. However, reports of male/female are alternated during the academic years, where males predominate in the period 2005-2009; while females dominate during the year 2004-2005 and 2009-2010.

Referring to gender differences in full time academic staff with title of Scientific Research Master, there are no significant differences through academic years in the study (Graphic 8, right). Until the academic year 2007-2008 females have dominated compared to men with a ratio 2:1 but after that year the result is reversed and dominated by males. At the end of the study period the ratio is approximately 1:1.

In the following graphic is presented the percentage of full time academic staff with the title of "Assistant professor", by gender and academic years '04 - '10.

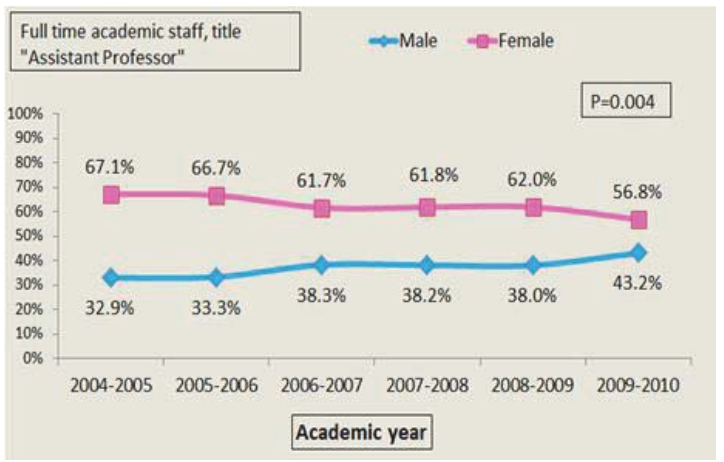

Graphic 9. Percentage of full time academic staff, "Assistant Professor" titled, by gender and academic years '04-'10.

Furthermore, the gender differences are obvious and statistically significant among the full time academic staff with title of Assistant Professor, as it is shown in Graphic 9. The largest percentage of Assistant Professors is females, during all academic years of the study. But, over the years, it is noticed a consistent, rapid and continuing decrease of in this gender difference: in 2004-2005 the ratio females /males of full-time professors with the title of Assistant Professor in the higher education was 2: 1 while in 2009-2010 the ratio is 1.3:1 (Graphic 9).

\subsection{Part-time academic staff}

In the following graphics is shown the percentage of part time academic staff with the title of "Professor" and "Associate Professor", by gender and academic years '04 - '10.
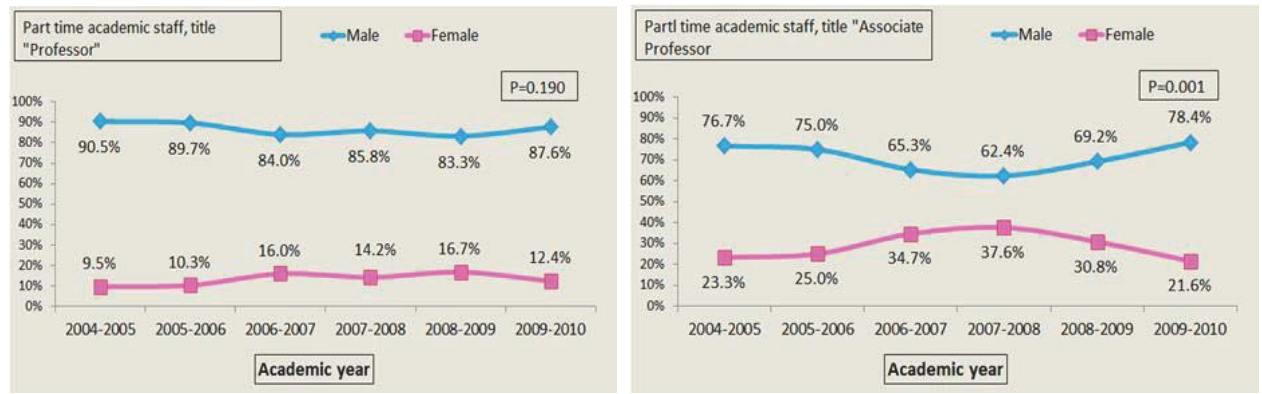

Graphic 10. The percentage of part-time academic staff with the title of "Professor" and "Associate Professor", by gender and during academic years '04-'10.

As it is shown in Graphic 10 (left), the gender differences during the time are not statistically significant among the parttime academic staff with the title of Professor $(P=0.190)$. The largest percentage of part-time staff titled Professor is 
males. But, over the years, there has been a slight decrease of the gender difference: in 2004-2005 the ratio males I females of full-time professors with PhD in higher education system was 9.5:1, which has a maximum reduction in 2008 2009 where the ratio is 5:1, while in 2009-2010 the difference grows again and became 7:1 (Graphic 10, left).

Regarding to gender differences of part-time academic staff with the title of Assistant Professor, there exist statistically significant changes over time (Graphic 10, right). Thus, in each academic year the percentage of male with this title is almost more than twice higher than females with this title (except during academic year 2007-2008), and this difference remained more or less at these levels during all academic years of this study.

In the following graphics are shown the percentage of part-time professors with and without the title "Doctor", by gender and academic years '04 - '10.
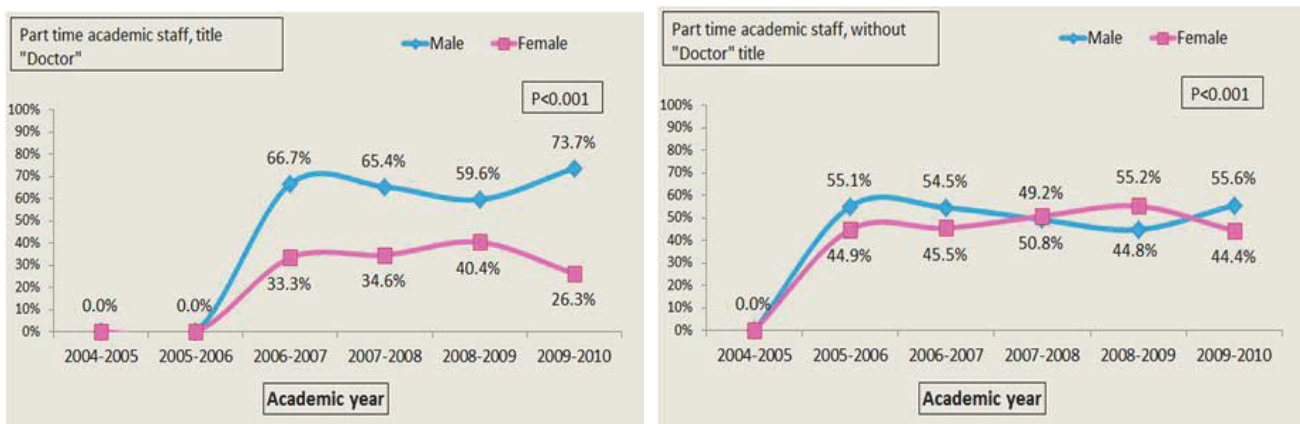

Graphic 11. The percentage of part-time professors with and without the title "Doctor", by gender and academic year '04'10.

Gender differences of part-time academic staff with Ph.D. are statistically significant $(P<0.001)$, as it is shown in Graphic 11, left. The largest percentage of staff titled Doctor is males in all academic years in this study (except 2004-2005 and 2005-2006). But, over the years, there is observed an oscillation of this gender difference: in 2006-2007 the ratio males/females of part-time professors with a Ph.D. in higher education system was 2:1, then the difference was maximally in year 2008 -2009 (ratio 1.5:1) while in 2009-2010 the ratio was 2.8:1 (Graphic 11, left).

Regarding the gender differences in full time academic staff without $\mathrm{PhD}$, there are significant differences during the academic years of the study (Graphic 11, right). But gender tendencies do not follow a clear model since that sometimes the domination belongs to males and others women are who make up the majority in specific academic years. However, gender differences are small here.

In the following graphics is presented the percentage of part time academic staff with title of "Assistant professor" and those without titles, by gender and '04 - '10 academic years
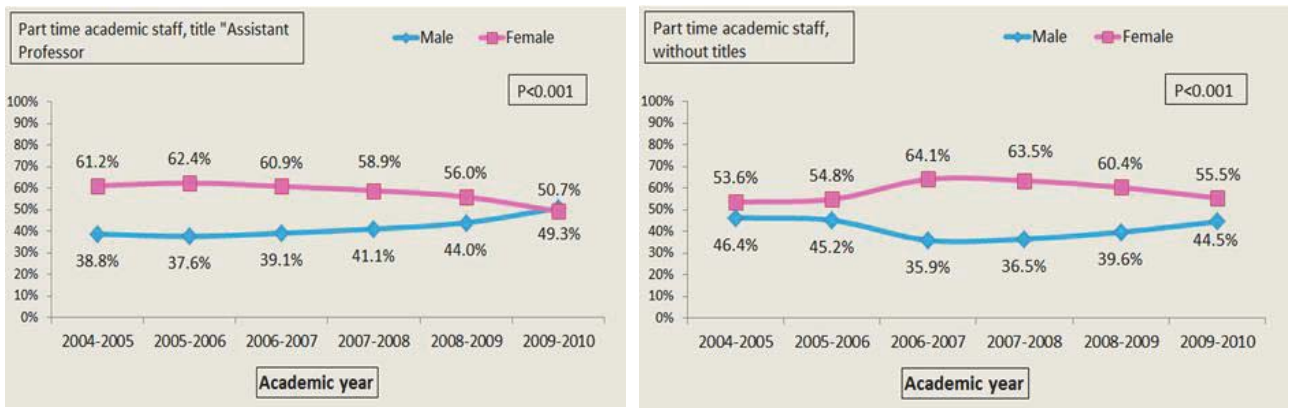

Graphic 12. Percentage of part time academic staff with title of "Assistant professor" and those without titles, by gender and '04 - '10 academic years 
Gender differences of part-time academic staff with title of Assistant Professor are statistically significant and obvious, as it is shown in Graphic 12, left. The largest percentage of part-time Assistant professors is female, in all academic years of the study. But, over the years, there is noticed a continuous and slight decrease of this gender difference: in 2005-2006 the ratio females/males of part-time professors with the title of Assistant Professor in higher education system was 1.7:1 while in year 2009-2010 this ratio was approximately 1:1 (Graphic 12 left).

Regarding to part-time academic staff without titles, the highest percentage is females. The gender differences were maximally observed in the academic year 2006-2007 (1.8:1 ratio on favor of females) and then gender differences gradually were reduced by achieving the ratio 1.2:1 ratio in favor of females, in academic year 2009-2010 (Graphic 12, right). The differences are statistically significant $(P<0.001)$.

\section{Data Interpretation/Conclusions}

\subsection{Graduated students in higher education of public and private institutions}

The percentage of females that graduated in the higher public education full time is bigger than that of males in every academic year in the study. The general trend is that the percentage of females graduated in higher public education full time has significantly decreased throughout the academic years in the study, even though it increases in the year 20092010. The report females/males graduated in higher public education full time was higher in the year 2005-2006 (respectively 2.6:1) and lower in the year 2008-2009 (respectively 1.6:1).

Also, the percentage of females graduated in higher public education part time is visibly higher than that of males in every academic year in this study. There is a tendency that the report is to be restrained during the years.

Even regarding graduations in the higher public education distance learning system, the percentage of graduated females prevails over the percentage of graduated males in every academic year in this study. The ratio females/males graduated in this educational profile fluctuates throughout the years, varying from 1.3:1 in the year 2004-2005 ( the lowest ratio) to 2.5:1 in 2009-2010 ( the highest ratio).

However, according to the percentages of graduations in higher private education full time system, gender trends do not reflect any obvious model, by being alternated from time to time.

Gender differences by type of diploma are significant among graduations of full-time students in public higher education, branch of Education Sciences. In any type of diploma, the vast majority of graduates are women: $85 \%$ of DNP graduates are women, $67.9 \%$ in DIND and $72.4 \%$ in MNP.

\subsection{Graduated students in public and private institutions of higher education by fields of study and type of diploma}

The similar tendencies are observed in terms of the percentage of women full-time graduated in public higher education on Humanitarian and Art branch sciences, by type of diploma, where they (females) constitute the vast proportion of graduates towards males, for every type of received diploma in this study.

Gender differences in graduation of full-time students in public higher education, branches of Social Sciences, Business and Law by type of diplomas are significant. In any type of diploma, except MND in this branch, the majority of graduates are women. More outlined gender differences are observed in the DND where for each graduated make there is an average of 6.2 graduated females, while the smallest gender differences belong to graduations in MND where males actually occupy a larger proportion than females (ratio male / female is 1.3:1).

In the branch of Nature Sciences, gender differences by type of diploma are also meaningful. In each type of diplomas, expect PhD degree, the majority of graduates are women. Gender differences are more observed in the DND, where for each graduated male there is an average of 5.4 graduated female and fewer gender differences belong to the Ph.D. degree because males have a larger proportion than females in this branch (ratio male / female is 1.7:1).

Gender differences by type of diploma are significant in full time graduated students of public higher education, branch of Engineering Sciences. In any type of diploma of this branch, the majority of graduates are males. Ratio male/female by type of diploma varies from 1.4:1 in DND to 1.8:1 in DIND.

In the branch of Agriculture-Veterinary, for each type of diploma except DND, the majority of graduates are males. In MNP, $100 \%$ of graduates are males while in DIND approximately one in five graduates is a male.

Statistical data for Europe show that many young people are affected by gender stereotypes in their occupational choices, and therefore it is necessary that career counselors should be more aware of the importance of gender equality in order to challenge existing prejudices of students and cultures within the school and its employees (Arnot et al., 1999). 
The findings show that girls and boys are interested in specific parts of the science. For example, a study conducted by Haussler and Hoffman $(1997,1998)$ with children aged 11-16 in different countries of Germany, showed that girls were less interested in physics than boys, while boys and girls were interested in aspects of science, for example, while talking about physics, girls were focused more on the concepts of light, sound and heat and less on mechanics, electricity and radioactivity. Haussler and Hoffman concluded that girls were more interested on arts, medicine and counseling while boys choose physics as an opportunity to work in research or technical field (Haussler \& Hoffman, 1997, 1998). As a conclusion, they argue that while gender-based interests are not very significant, girls are more likely to choose subjects that are most useful in their daily lives (Eurydice 2006).

Despite several improvements are made, the existence of gender differences in scientific subject has led the feminist researches and professors of these subjects to find and implement new ways of "doing science" and giving answers to scientific questions. Researchers believe that such developments are necessary because otherwise the scientific knowledge and applied methods will only reinforce ideologies and power relations that exist in society (Brickhouse, 2001). The qualities as rationality, which are the basis of scientific development, are usually associated with the masculine way of thinking. These arguments have led to the development of alternative curricula which can help students, especially girls, to contribute more on science and on improvement of teaching practices aimed at changing the traditional scientific hierarchies (Brickhouse, 2001).

\subsection{Full time academic staff}

The gender differences of PhD full-time academic staff are obvious and statistically significant. The vast percentage of full-time staff, titled Professor is male. But over the years, there is noticed a relatively rapid and continuing decrease of this gender difference: in 2004-2005 academic year the ratio among male/female of full-time professors with PhD in higher education system, was 7.3:1 while in 2009-2010, which marked the largest decrease of gender differences, this report became 2.8:1

Referring to gender differences of full time academic staff with the title of Assistant Professor, there are no statistically significant changes over time. In each academic year the percentage of male with this title is more than twice higher than that of female with the same title, and this difference remained more or less at these levels during the entire academic years of this study.

The largest percentage of staff with Doctor Title is males, in all academic years of the study. During the years, there is seen a very rapid and continuing decrease of this gender difference: in 2004-2005 the ratio male/female of fulltime professors with a Ph.D. in higher education system was 2.3:1 and in year 2009 - 2010 this ratio was 1.4:1

Gender differences are statistically significant among the full time academic staff that has the title of Scientific Researches Directors. Reports of males/females are alternated during the academic years, where males predominate in the period 2005-2009; while females have dominated during the years 2004-2005 and 2009-2010.

Regarding gender differences of full time academic staff with title of Scientific Research Masters, until the academic year 2007-2008 females have dominated compared to males with a ratio of 2:1, but after that year the result is reversed and dominated by males. At the end of the study period the ratio was approximately 1:1.

The largest percentage of full time Assistant Professors is females, during all academic years of the study. But, over the years, it is noticed a consistent, rapid and continuing decrease of in this gender difference: in 2004-2005 the ratio females /males of full-time professors with the title of Assistant Professor in the higher education was 2: 1 while in 2009-2010 the ratio was 1.3:1.

\subsection{Part-time academic staff}

The major percentage of part-time staff with the title of Professor is males. During the years, it is noticed a slight decrease of this gender difference: in year 2004-2005 the ratio males /females of full-time professors with PhD in higher education system was 9.5:1, than maximum reduction occurs in 2008-2009 where the ratio was 5:1, while in year 20092010 the difference was increased again and the ratio became 7:1.

According to gender differences of part-time academic staff with the title of Assistant Professor, every academic year the percentage of males with this title is almost twice higher than females with this title (except during academic year 2007-2008), and this difference has remained more or less at these levels during all academic years of this study.

The largest percentage of part-time staff with PHD degree is males, during all academic years of this study (except 2004-2005 and 2005-2006). But, over the years, there is observed an oscillation of this gender difference: in 2006-2007 
the ratio males/females of part-time professors with a Ph.D. in higher education system was 2:1, then the difference was maximal in the year 2008 -2009 (ratio 1.5:1) while in 2009-2010 the ratio was 2.8:1.

Regarding gender differences of full time academic staff without $\mathrm{PhD}$, the changes do not follow a clear model since that sometimes the domination belongs to males and other times women are those who make up the majority in certain academic years. However, gender differences are lower.

The largest percentage of part-time Assistant professors is female, in all academic years of the study. But, over the years, there is noticed a continuous and a slight decrease of this gender difference: in 2005-2006 the ratio females/males of part-time professors with the title of Assistant Professor in higher education system was 1.7:1 while in year 2009-2010 this ratio became approximately 1:1.

Regarding part-time academic staff without titles, the highest percentage is females. The gender differences were maximally observed in the academic year 2006-2007 (1.8:1 ratio in favor of females) and then gender differences gradually were reduced by achieving the ratio 1.2:1 in favor of females, in academic year 2009-2010.

A considerable number of researches and data have further clarified the academic challenges that women are facing every day. These data include unequal payment between employees at the same level, the differences between women's representation in universities and the percentage of students, accepted perceptions and models of behavior that have led to discrimination against women, while they attend university (Barbezat and Hughes, 2006; Morley, 2005; West and Curtis, 2006). Current researches are analyzing why these challenges can occur and what can be done to change the trend.

According to some researchers, higher education is in crisis (Gappa, Austin and Trice, 2007; Hult, Callister and Sullivan, 2005; Schuster and Finkelstein, 2006). Although the number of women who teach in universities has increased in the last two decades, there is still no evidence of the increase of women, with Professor Title.

The theorists of human capital give some arguments about the causes of gender discrimination for promotion of career progress:

- One of these arguments is that gender differentiations in levels of promotion are made because of gender differences in hiring, education and experience. It is thought that women are engaged more with the family, thus leaving aside their career development.

- Also, differences in education are related with promotions.

- A title offers a higher level of payment and less direct involvement in auditors, this means less teaching workload. It seems clear that even in universities, where the number of female employees is quite high, males remain well represented and the monthly incomes are higher.

- Women receive less training and have fewer years of experience within various institutions. This makes their representation in managerial and leadership levels lower than that of men.

Hult, Callister and Sullivan (2005, p 55) suggest five steps that can significantly improve the atmosphere at universities:

1. Reassessment of all departments and higher education institutions to locate underrepresented gender programs and directions by providing training for managers on inclusion strategies and/or recruitment in the future.

2. Making transparent the fiscal scheme and decision-making process in universities.

3. Giving priority to balance of work/home, in order to provide flexibility in the use of official work permits.

4. Inclusion but not overrepresentation of women in committees.

5. Creation of policies that encourage interdisciplinary in the career.

6. Encouraging of cooperation between faculty researchers.

Academic and career achievements remain male-dominated fields in Albania. The percentage of women involved in career and academic achievement continues to be very low in Albania, a figure that is attributed to gender inequality in terms of attendance and benefit from higher levels of education. Even though the number of women and girls who teach in universities has increased in the last two decades, and the number of women and girls graduated in higher education system is twice, but there are not still evident projections of a significant increase in the number of women with professor

In Albania, there is no lack of skilled and qualified women but that "our society has historically been open to men achievements in the field of career than women. For many years in Albania, women and girls have the largest number of graduates in higher education. But referring to their socio-economic status, the situation still needs to be improved.

Women and girls in Albanian are facing the feminization of poverty and their social status is still far from their aspirations and does not respond to their investments in education. Certainly, except education, there are other factors affecting this situation such as the economic level, culture level, mentality, traditions, stereotypes, gender division of 
labor, legislation, geographic area, etc. (GADC, 2006).

The different impact that have on men and women the development initiatives (without excluding girls and boys) can be measured only if the indicators that assess it are sensitive to gender issues, which means that every individual needs and interests should be illustrated in program, regardless of gender. Sensitive indicators of gender can serve as practical tools because the information obtained from them can be used to promote initiatives aiming at achieving gender equality and the empowerment of women and girls.

Defined as the equality in all spheres between men and women, both public and private, gender equality means equal access and control on resources and benefits, equal participation in political decision-making and equality on law for women and men. Gender equality, in itself, is not only a democratic necessity, but also an economical, social and political necessity for the reduction of poverty and integration of Albania in the development processes.

\section{References}

Arnot, M., David, M., \& Weiner, G., 1999. Closing the Gender Gap: Postwar educational and social change. Cambridge: Polity Press.

Barbezat, D. A., and Hughes, J. W. "Salary Structure Effects and the Gender Pay Gap in Academia." Research in Higher Education, 2006, 46(6), 621-640.

Brickhouse, N.W., 2001. Embodying science: a feminist perspective on learning. Journal of Research in Science Teaching, 38(3), pp. 282-295.

Eurydice, 2006. Science teaching in schools in Europe. Brussels: Eurydice.

Häussler, P. \& Hoffmann, L., 1997. An den Interessen von Jungen und Mädchen orientierter Physikunterricht [Physics lessons orientated toëards the interests of boys and girls]. Kiel: IPN.

Häussler, P. \& Hoffmann, L., 1998. Chancengleichheit für Mädchen im Physikunterricht [Equality of girls in physics lessons]. [Online] Available at: http://lise.univie.ac.at/artikel/hoffmann.htm.

Hult, C., Callister, R., and Sullivan, K. "Is There a Global Warming Toward Women in Academia?" Liberal Education, 2005, 91(3), 5057.

Morley, L. "Opportunity or Exploitation? Women and Quality Assurance in Higher Education." Gender and Education, 2005, 17(4), 411429.

MoLSAEO, 2011. Harmonized Indicators on Gender Equality and Women's Status in Albania. Tirana. Alb Paper.

Ministry of Education and Science, 2011, "Annual Statistical Report 2009-2010".

Neimanis, A., 2001. Gender mainstreaming in practice: A handbook. UNDP Regional Gender Programme of the United Nations Development Programme's Regional Bureau for Europe and the CIS (UNDP RBEC). New York: UNDP.

Schuster, J. H., and Finkelstein, M. J. The American Faculty: The Restructuring of Academic Work and Careers. Baltimore, Md.: Johns Hopkins University Press, 2006.

Gender Alliance for Development, 2004. Gender Mainstreaming in Education. Tirana. Pegi Publishing House.

Gender Alliance for Development, 2006. Gender mainstreaming in policies and strategies. Tirana. Pegi Publishing House.

Gappa, J. M., Austin, A. E., and Trice, A. G. Rethinking Faculty Work: Higher Education's Strategic Imperative. San Francisco: JosseyBass, 2007.

West, M. S., and Curtis, J. W. "Organizing Around Gender Equity." In J. W. Curtis and M. S. West (eds.), AAUP Faculty Gender Equity Indicators 2006. Washington, D.C.: American Association of University Professors, 2006. 